Александр Внутских, Светлана Гасумова, Мария Иванова,

Елена Малкова, Мария Петрова

\title{
СОЦИАЛЬНЫЕ ПРЕДПРИЯТИЯ И СО НКО В ПЕРМСКОМ КРАЕ: ПРОБЛЕМЫ И ПЕРСПЕКТИВЫ РАЗВИТИЯ
}

В обзоре рассмотрены специфика современных практик социально ориентированных некоммерческих организаций (СО НКО) и социального предпринимательства (СП) в Пермском крае. Определены отличительные черты и элементы социального предпринимательства с учетом существования разных подходов к объяснению самого явления. Феномен показан в дуалистической форме, т.к. рассматривается с одной стороны, как частный случай бизнеса, с другой-как элемент гражданского общества, поскольку представляет собой возможность комбинирования коммерческой устойчивости и социальной пользы от инвестиций. Исследуются уровень развития и меры институциональной поддержки организаций СП и СО НКО в Пермском крае. В регионе отмечается не только количественный рост негосударственного сектора социальной сферы, но и успешность отдельных пермских социально ориентированных организаций на федеральном уровне. В крае сформирована база грантовой помощи некоммерческим организациям, функционирует ресурсный центр, обеспечивающий организационную и информационную поддержку НКО и СП. Установлено, что, несмотря на предполагаемый долговременный характер и постоянство бизнес-процессов, социальное предпринимательство в Пермском крае не достигло уровня развития СО НКО как в отношении результативности в решении проблем социальной сферы, так и в отношении формирования положительного имиджа. Исследователи связывают данный факт с недостаточностью информационной открытости и прозрачности работы СП

Александр Юрьевич Внутских - д.философ.н., профессор, кафедра культурологии и социально-гуманитарных технологий, кафедра философии, философско-социологический факультет, Пермский государственный национальный исследовательский университет, Пермь, Россия. Электронная почта: avnut@inbox.ru

Светлана Евгеньевна Гасумова- к.социол.н., доцент, кафедра социальной работы и конфликтологии, кафедра информационных технологий, Пермский государственный национальный исследовательский университет, Пермь, Россия. Электронная почта: svetagasumova@yandex.ru

Мария Михайловна Иванова- аспирант, факультет социологии, Санкт-Петербургский государственный университет, Санкт-Петербург, Россия. Электронная почта: ivanova.mar-9308@yandex.ru

Елена Вячеславовна Малкова- к.философ.н., проректор по молодежной политике, Пермский государственный национальный исследовательский университет, Пермь, Россия. Электронная почта: ev-malkova@yandex.ru

Мария Дмитриевна Петрова- преподаватель, кафедра культурологии и социально-гуманитарных технологий, философско-социологический факультет, Пермский государственный национальный исследовательский университет, Пермь, Россия. Электронная почта: psupmd@gmail.com 
в Пермском крае. Также рассматриваются успешные практики СП и СОНКО. Значительная часть последних применяет технологию обратной связи как ресурс для минимизации обезличенности акта благотворительности. Многие СОНКО диверсифицируют источники финансирования, в т.ч. за счет регулярных платежей со стороны многочисленных частных доноров путем онлайн-фандрайзинга. Перспективы развития СП и СОНКО в регионе авторы связывают с популяризацией идей социального предпринимательства, с реализацией обучающих и акселерационных программ, с повышением информационной доступности и максимальной открытости деятельности организаций, что будет способствовать формированию позитивного общественного имиджа, а также с совершенствованием законодательного регулирования отдельных видов деятельности социальных предпринимателей и открытием новых сфер деятельности СП.

Ключевые слова: социальное предпринимательство, социально ориентированные НКО, Пермский край

DOI: 10.17323/727-0634-2021-19-1-166-176

Расширение участия социально ориентированных некоммерческих организаций и социальных предприятий в оказании социальных услуг является одним из приоритетных направлений развития сферы социального обслуживания в России. Особый интерес для государства представляет повышение социальной ответственности бизнеса и развитие социального предпринимательства (СП). Цель СП- стимулировать общественные преобразования и одновременно решать локальные социальные проблемы. Специфика СП заключается в ценностном потенциале для общества (Tanvi, Rishav 2018). СП может пониматься как частный случай бизнеса, который ориентирован в первую очередь на извлечение прибыли и направлен на создание и поддержание социальной ценности при постоянной вовлеченности в инновационную деятельность (Dees 1998). Сторонники другого подхода полагают, что главным отличием СП от обычного ведения бизнеса является трактовка основной цели: вместо прибыли- конструирование ценностей, направленных на создание социального блага путем стимулирования социальных изменений или удовлетворения социальных потребностей (Баталина и др. 2020). Роджер Мартин и Салли Осберг считают, что специфика СП заключается в понимании основной цели как деятельности по социальному преобразованию на основе собственных ресурсов, направленной на целевые группы (Martin, Osberg 2007). Очевидно, что такое понимание деятельности СП делает ее схожей с деятельностью СОНКО.

Для оценки эффектов СП учитывается комплекс факторов разного уровня. На макроуровне - социально-демографические, социально-трудовые показатели, уровень и качество жизни населения. На микроуровне выделяются такие показатели, как срок окупаемости и результативность 
социального проекта, коэффициент социальной рентабельности и социальный индекс (Плюхина 2016: 1571). Важными маркерами эффективности СОНКО и СП могут также служить проработанность законодательной базы, объем институциональной поддержки, прозрачность и информационная открытость организации, ее способность аккумулировать различные источники финансирования (Старшинова, Бородкина 2020: 422).

В контексте социальной политики СП анализируется как инструмент решения социальных проблем (Moskovskaya, Soboleva 2016) или как технология социальной работы с уязвимыми категориями населения (Germak, Singh 2019). Сравнительно немногие публикации посвящены применению социальных инноваций, реализованных СП в различных сферах жизни общества (Konda et al. 2016; Карпова, Богданова 2019). В нашем исследовании мы также обращаем внимание на социальные группы, с которыми работают СП и СО НКО Пермского края.

\section{Уровень развития СО НкО и СП в Пермском крае}

Пермский край представляет интерес для изучения СП. По итогам 2018 г., согласно опубликованному Рейтингу реализации механизмов поддержки СОНКО и СП, регион занял шестое место, отстав от замыкающей пятерку регионов-лидеров Республики Башкортостан менее чем на 1,5 балла (Министерство экономического развития России 2018). Кроме того, в этом рейтинге регион занял второе место по доле работников негосударственных организаций в общей численности работников, занятых в социальной сфере, и четвертое место по удельному весу негосударственных организаций социального обслуживания в общем количестве организаций социального обслуживания всех форм собственности. Отметим не только количественный рост негосударственного сектора социальной сферы в крае, но и признанные на федеральном уровне успехи отдельных пермских социально ориентированных организаций, в первую очередь СОНКО. В частности, по итогам X конкурса добровольных публичных годовых отчетов НКО обладателями «Золотого стандарта» стали благотворительные фонды «Берегиня» и «Дедморозим», ПРОО «Счастье жить!» (Форум Доноров 2020).

Работа СП в регионе пока реже удостаивается положительных оценок со стороны общественности и СМИ. Независимая оценка качества социальных услуг в Пермском крае (Гасумова 2020) показала невысокий уровень эффективности деятельности коммерческих организаций, получивших статус поставщиков социальных услуг. Среди причин низкой эффективности называются недостаточное финансирование и узкая специализация региональных СП. В последние годы в Пермском крае в формате СП преимущественно развиваются детские центры и частные дома для проживания пожилых людей. Причем если говорить о последних, органы государственной власти совместно с правоохранительными ор- 
ганами регулярно выявляют недобросовестных предпринимателей, предоставляющих услуги ненадлежащего качества, опасные для здоровья и жизни получателей. Стоит констатировать, что развитие СП в Пермском крае отстает от развития СОНКО как в отношении результативности в решении проблем социальной сферы, так и в отношении формирования положительного имиджа СП.

\section{Формы поддержки и институциальный контекст развития социально ориентированных организаций в Пермском крае}

Согласно базе, опубликованной на информационном портале Перми, в крае работает 879 СО НКО. Около 250 из них получают муниципальную поддержку (Муниципальное... 2020). Что же касается СП, то их реестр до сих пор не создан, соответственно, их число можно оценивать лишь приблизительно. Например, эксперт по социальному предпринимательству, директор международного центра импакт-инвестиций «Галилео» Сергей Витальевич Пономарев в интервью, проведенном нашей исследовательской группой, сообщил, что в Пермском крае работают до 1,5 тысяч СП, в основном это детские центры и частные дома пожилых. Считается, что именно этим типам СП в первую очередь необходимо создать условия для присвоения статуса социальных предприятий и включения в будущий Реестр, т. к. они активно функционируют и «рыночно востребованы» (Сайт губернатора... 2020). Пономарев отмечает, что для региональных СП следующими возможными «точками роста» могут стать экологические проекты, помощь людям с зависимостями и асоциальным поведением, жертвам насилия. Все эти направления работы пока мало востребованы среди региональных СП из-за низкой поддержки как государства, так и других инвесторов.

Напротив, спектр деятельности поддерживаемых государством СОНКО достаточно широк. Так, в рамках Конкурса социальных и гражданских инициатив в 2018 г. из отобранных проектов 45\% были направлены на поддержку ветеранов, 23 \% - на развитие патриотического воспитания, $10 \%$ - на развитие сфер образования, просвещения, науки, культуры, искусства, здравоохранения, профилактики и охраны здоровья граждан, еще $10 \%$ из поддержанных проектов относятся к сфере добровольчества и благотворительности; остальные поддержанные проекты направлены на развитие информационного пространства, детского/молодежного движения (Молодежный эксперт 2020). СП в Пермском крае существуют в основном за счет реализации коммерческих проектов, имеющих социальный аспект. Некоторые из них получали поддержку фонда «Наше будущее». Однако в 2019 г. деятельность Фонда на территории Пермского края была прекращена, и у региональных СП осталась только одна возможность получения софинансирования - быть включенными в реестр поставщиков социальных услуг (Министерство социального... 2020). 
Анализ нормативно-правовой базы регулирования деятельности и поддержки СОНКО и СП в Пермском крае показал, что на сегодняшний день она достаточно сформирована и содержит в себе ряд действенных механизмов поддержки. Помимо федеральных законов (см. Ф3 № 7, 209, 442), на региональном уровне деятельность СП и НКО регулируется законом № 174-ПК от 7 марта 2013 г. Приказ Министерства экономического развития РФ от 29 ноября 2019 г. № 773 регулирует присвоение статуса социального предприятия, дающего право социальным предпринимателям получать субсидии. Именно на основе критериев, установленных этим законом, комиссия, в которую входят специалисты Центра поддержки предпринимательства «Мой бизнес», эксперты региональных министерств экономического развития, а также промышленности и торговли, предполагает формировать реестр СП.

Институциальная поддержка СОНКО и СП в Пермском крае осуществляется Департаментом общественных проектов Администрации губернатора Пермского края (Сайт губернатора... 2020) и Ресурсным центром, реализующим информационную, консультационную, образовательную и организационную поддержку (Ресурсный центр... 2020). Министерство промышленности, предпринимательства и торговли Пермского края проводит мероприятия для социальных предпринимателей: ежегодный краевой форум, освещающий реализацию социально-предпринимательских проектов и возможности привлечения ресурсов для их запуска (Полякова 2018). Проект «Развитие социального предпринимательства в Пермском крае» реализует акселерационную программу «Школа социального предпринимательства». Однако эта программа не пользуется у жителей региона популярностью. С 2016 г. обучение прошли около 100 человек, только половина из них действительно внедрили свои идеи в муниципальных образованиях Пермского края (Корпорация развития... 2020).

\section{Лучшие практики пермских СП и СО Нко}

Обзор успешных пермских СП и СО НКО показал, что некоторые из них являются примерами лучших российских практик и могут быть предложены для тиражирования в других регионах. К числу успешных организаций социальных предпринимателей Пермского края можно отнести деятельность детского центра развития «Витамин роста», которая направлена на создание условий для дошкольного и дополнительного детского образования в Сылвенском сельском поселении Пермского муниципального района. Миссия центра может быть выражена слоганом «Ломаем стереотип "Дети из сел и деревень не развиты в области дополнительного образования"». В центре развития осуществляется подготовка к школе, работает логопед, есть театральная студия и секции эстетической гимнастики, ритмики, ушу, развития памяти и техники чтения, игры на гитаре. Центр выступает постоянным партнером ряда социальных 
проектов, например, «Школа особого развития "Краски жизни"» для семей, воспитывающих детей с инвалидностью.

АНО «Экотур» (2020) организует походы и сплавы выходного дня по примечательным местам и рекам Урала. В качестве социального компонента предпринимательской деятельности организации выступают проекты, направленные на организацию досуга для семей с детьми с ограниченными возможностями здоровья. В 2018 г. АНО «Экотур» организовала деятельность Инклюзивного краеведческого лагеря «Ермак»; в 2019 г. при поддержке гранта «ОМК-Партнерство» реализован проект «Театр на воде» для детей с ограниченными возможностями здоровья, детей из многодетных и малообеспеченных семей; а в 2020 г. при поддержке Фонда президентских грантов проведен инклюзивный краевой семейный фестиваль «Мы- внуки победителей» для семей с особыми детьми, многодетных и малообеспеченных семей Пермского края.

Несмотря на активную деятельность и множество реализованных проектов, рассмотренные СП не имеют официальных сайтов с подробной информацией и сервисами для более широкого взаимодействия с обществом и государством, есть только страницы в социальных сетях, на которых в основном размещаются коммерческие предложения.

Лучшие СО НКО края характеризуются большей информационной открытостью и прозрачностью деятельности. Среди них - благотворительные фонды (Дедморозим 2020; Берегиня 2020) и Пермская краевая общественная организация «Счастье жить!» (Счастье жить! 2020). Эти организации сосредоточены на поддержке тяжелобольных детей, детейинвалидов, детей-сирот. Они достаточно «узнаваемы» и благодаря этому успешно привлекают серьезное финансирование из различных источников, в т.ч. путем краудфандинга, чем и обеспечивают устойчивость своей работы. На официальных сайтах организаций представлены stories детей, которые нуждаются в помощи или уже получили ее, подробные данные о ежемесячных поступлениях и расходовании средств, детальные годовые отчеты и аудиторские заключения, есть удобные онлайн-сервисы для потенциальных частных доноров с возможностью реализовать ежемесячные пожертвования. Представляется, что и региональные СП могли бы взять на вооружение некоторые организационные и информационные технологии и подходы, используемые этими СО НКО.

\section{Заключение}

Уровень институциальной поддержки социально ориентированных организаций Прикамья оценивается как довольно высокий. Однако качество деятельности этих организаций, особенно СП, оставляет желать лучшего. Показательно, что немногие СП подают заявки на включение в реестр поставщиков социальных услуг. Хотя в последние годы в регионе 
активно развивается предпринимательская деятельность по стационарному социальному обслуживанию пожилых граждан и инвалидов, краевым Министерством социального развития конкретные требования к такого рода организациям не сформулированы. Нет даже ограничения по минимальной продолжительности работы таких организаций на рынке социальных услуг, соответственно, каким-либо проверкам со стороны профильного министерства они не подлежат.

В целом жизнеспособная модель социально ориентированных организаций, которая бы могла совместить организационную эффективность и интересы развития социальной сферы, в Пермском крае еще только вырабатывается. Пока в большей мере это удается региональным СОНКО, нежели СП, причем лучшие СОНКО характеризуются и наибольшей информационной открытостью и прозрачностью, минимизируют обезличенность акта благотворительности путем обратной связи, способны диверсифицировать источники поступления средств, в т. ч. за счет удобных для частных доноров.

Положительный опыт реализации проектов части пермских СП представляет собой достаточно локальные и маловлиятельные истории. Для серьезных позитивных изменений в этой сфере необходимо развитие мотивации наряду с продолжением институциональной поддержки и совершенствованием законодательного регулирования деятельности СП. Для этого необходимо повышать информационную открытость и прозрачность работы СП, что будет способствовать как формированию позитивного имиджа, общественной мотивации к этой деятельности, так и диверсификации финансирования. Следует задуматься и о расширении сферы приложения их усилий. В этом смысле информационные и организационные наработки СОНКО могут быть полезными для СП.

\section{Выражение признательности}

Работа выполнена в СПбГУ при поддержке РНФ, проект № 19-18-00246.

Редакция благодарит программу Университетское партнерство за поддержку и возможность опубликовать данную статью.

\section{Материалы для анализа}

Берегиня (2020) Доступно по ссылке: https://fondbereginya.ru/podrobnee-o-fonde (дата обращения: 6 апреля 2020).

Дедморозим (2020) Доступно по ссылке: https://dedmorozim.ru (дата обращения: 6 апреля 2020).

Закон Пермского края (2013) О государственной поддержке сочиально ориентированных некоммерческих организаций в Пермском крае № 174-ПК от 07.03.2013. 
Корпорация развития малого и среднего предпринимательства Пермского края (2020) Акселерационная программа «Школа сочиального предпринимательства». Доступно по ссылке: https://соцпред.цпп-пермь.pф/shkola_soczialnogo_predprinimatelstva/ (дата обращения: 6 апреля 2020).

Министерство социального развития Пермского края (2020) Реестр поставщиков социального обслуживания. Доступно по ссылке: $\mathrm{https://minsoc.permkrai.ru/sotsialnoe-}$ obsluzhivanie/reestr-post/ (дата обращения: 6 апреля 2020).

Министерство экономического развития России (2018) Результаты рейтинга субъектов РФ по итогам реализации механизмов поддержки СОНКО и социального предпринимательства. Доступно по ссылке: http://nko.economy.gov.ru/portalnews/ $\mathrm{read} / 4606$ (дата обращения: 28 апреля 2020).

Молодежный эксперт (2020) Типология сощиальных предпринимателей. Доступно по ссылке: https://vk.com/@molodexpert-tipologiya-socialnyh-predprinimatelei-tipvtoroi (дата обращения: 28 апреля 2020).

Муниципальное образование г. Пермь (2020) Реестр СОНКО. Доступно по ссылке: https://www.gorodperm.ru/actions/social-link/society/public_organization/nko/ (дата обращения: 16 января 2021).

Общественная палата Российской Федерации (2020) «Точка отсчета»: объявленьл итоги Х конкурса публичных годовых отчетов НКО. Доступно по ссылке: https:/ www.oprf.ru/press/news/2617/newsitem/52334 (дата обращения: 1 апреля 2020).

Приказ Министерства экономического развития (2019) Об утверждении Порядка признания субъекта малого или среднего предпринимательства сочиильным предприятием № 773 от 29.11.2019.

Ресурсный центр СОНКО Пермского края (2020) Доступно по ссылке: https:/ vk.com/sonko59_(дата обращения: 1 апреля 2020).

Сайт губернатора и Правительства Пермского края (2020) Доступно по ссылке: https:/ permkrai.ru/news/v-permskom-krae-sformiruyut-edinuyu-bazu-sotsialnykh-biznesmenov-/ (дата обращения: 6 апреля 2020).

Счастье жить! (2020) Доступно по ссылке: https://happy59.com/about/ (дата обращения: 6 апреля 2020).

Федеральный закон (1995) Об основах сочиального обслуживания населения в Российской Федеращии № 195-ФЗ от 10.12.1995.

Федеральный закон (1996) О некоммерческих организащиях № 7-ФЗ от 12.01.1996.

Федеральный закон (2007) О развитии малого и среднего предпринимательства в Российской Федерачии № 209-ФЗ от 24.07.2007.

Федеральный закон (2013) Об основах сощиального обслуживания граждан в Российской Федеращии № 442-ФЗ от 28.12.2013.

Форум Доноров (2020) Победители конкурса «Точка отсчета»- 2019. Доступно по ссылке: http://www.donorsforum.ru/projects/tochka-otschyota/pobediteli/pobediteli-2019/ (дата обращения: 1 апреля 2020). 
Центр развития «Витамин роста» Сылва (2020) Доступно по ссылке: https://vk.com/ vitamin.rosta (дата обращения: 1 апреля 2020).

Экотур (2020) Доступно по ссылке: https://vk.com/splav_chusovoy (дата обращения: 29 апреля 2020).

\section{Список источников}

Баталина М., Московская А., Тарадина Л. (2020) Обзор опыта и концепиии социального предпринимательства с учетом возможностей его применения в современной России. М.: НИУ ВШЭ.

Гасумова С. (2020) Перспективные новшества в цифровизации социального обслуживания и их оценка руководителями социальных служб в Пермском крае. Omeчественный журнал социальной работы, 1 (80): 76-83.

Карпова Г., Богданова И. (2019) Роль и место предпринимательства в сфере туристских услуг. Известия Санкт-Петербургского государственного экономического университета, 3 (117): 74-80.

Плюхина А.А. (2016) Совершенствование методики оценки деятельности социальных предприятий. Российское предпринимательство, 17 (13): 1569-1582.

Полякова А.А. (2018) Социальное предпринимательство на примере Пермского края: значение, проблемы, перспективы. Экономика и бизнес: теория и практика, (7): $98-101$.

Старшинова А.В., Бородкина О.И. (2020) Деятельность НКО в сфере социальных услуг: общественные ожидания и региональные практики. Журнал исследований социильной политики, 18 (3): 411-428.

Dees G. (1998) Enterprising Nonprofits. Harvard Business Review, 76 (1): 54-67.

Germak J., Singh K. (2019) Social Entrepreneurship: Changing the Way Social Workers Do Business. Administration in Social Work, 34 (1):79-95.

Martin L., Osberg S. (2007) Social Entrepreneurship: The Case for Definition. Stanford Social Innovation Review, (33): 28-39.

Moskovskaya A., Soboleva I. (2016) Social Entrepreneurship in the System of Social Policy: International Experience and Prospects of Russia. Studies on Russian Economic Development, 27 (6): 683-688.

Konda I., Starc J., Rodica B. (2016) Social Challenges are Opportunities for Sustainable Development: Tracing Impacts of Social Entrepreneurship Through Innovations and Value Creation. Economic Themes, (53):215-233.

Tanvi G., Rishav R. (2018) Social Entrepreneurship: The Need, Relevance, Facets and Constraints. Journal of Global Entrepreneurship Research, 8 (9): 1-13. 
Alexander Vnutskikh, Svetlana Gasumova, Maria Ivanova,

Elena Malkova, Maria Petrova

\section{SOCIAL ENTERPRISES AND SO NPOS IN PERM KRAI: PROBLEMS AND PROSPECTS OF DEVELOPMENT}

This article is an overview considering the specifics of modern practices of SO NGOs and social entrepreneurship (SE) in the Perm Krai. The authors identify the distinctive features and elements of social entrepreneurship, considering of the different approaches to explaining the phenomenon itself. The phenomenon of social entrepreneurship has a dualistic character, on the one hand as a special case of business, on the other as a component of civil society, since it is an opportunity to combine commercial sustainability and social benefits from investment. The authors note not only the quantitative growth of the non-governmental sector of the social sphere in the region, but also the success of individual Perm SONGOs at the federal level. The region has a database of grant aid for non-profit organizations, and a resource center that provides organizational and informational support for NGOs and joint ventures. The authors indicate that, despite the supposed long-term nature and constancy of business processes, social entrepreneurship in the Perm Krai has not reached the level of development of SONGOs, both in terms of effectiveness in solving social problems, and to form a positive image of the joint venture. The authors associate the prospects of the development of SE and SONGOs in the region with the popularization of ideas of social entrepreneurship, with implementing training and acceleration programs, with the increase of information availability and the maximum openness of the activities of organizations that will promote a positive public image, and improving the legal regulation of activities of social entrepreneurs and the opening of new fields of activity of the joint venture.

Keywords: Social entrepreneurship, socially oriented NPOs, Perm Krai

DOI: 10.17323/727-0634-2021-19-1-166-176

\footnotetext{
Alexander Vnutskikh- Dr. Sci. (Phil.), Professor of the department of philosophy, Department of cultural studies and social and humanitarian technologies, Faculty of Philosophy and Sociology, Perm State University, Perm, Russian Federation. Email: avnut@inbox.ru

Svetlana Gasumova-Cand. Sci. (Soc.), associate professor, Department of social work and conflict studies, Perm State University, Perm, Russian Federation. Email: svetagasumova@yandex.ru

Maria Ivanova - PhD student, Faculty of Sociology, Saint-Petersburg State University, Saint Petersburg, Russian Federation. Email: ivanova.mar-9308@yandex.ru

Elena Malkova-Cand. Sci. (Phil.), Vice-Rector for youth policy, Perm State University, Perm, Russian Federation. Email: ev-malkova@yandex.ru

Maria Petrova- Assistant of the department of cultural studies and social and humanitarian technologies, Faculty of Philosophy and Sociology, Perm State University, Perm, Russian Federation. Email: psupmd@gmail.com
} 


\section{Acknowledgments}

This article was carried out with support of the Russian Science Foundation (RSF) according to scientific project no. 19-18-00246 'Challenges of Transformation of the Welfare State in Russia: Institutional Changes, Social Investment, Digitalization of Social Services,' implemented at Saint Petersburg State University.

\section{References}

Batalina M., Moskovskaya A., Taradina L. (2008) Obzor opyta $i$ kontseptsiy sotsial'nogo predprinimatel'stva s uchetom vozmozhnostey ego primeneniya $v$ sovremennoy Rossii [Review of the Experience and Concepts of Social Entrepreneurship, Taking into Account the Possibilities of its Application in Modern Russia]. Moscow: GU VShE.

Dees G. (1998) Enterprising Nonprofits. Harvard Business Review, 76 (1): 54-67.

Gasumova S. (2020) Perspektivnye novshestva v tsifrovizatsii sotsial'nogo obsluzhivaniya i ikh otsenka rukovoditelyami sotsial'nykh sluzhb v Permskom krae [Perspective Innovations in Digitalization of Social Services and Their Assessment by the Directors of Social Services in Perm Kray]. Otechestvennyy zhurnal sotsial'noy raboty [Domestic Journal of Social Work], 1 (80): 76-83.

Germak J., Singh K. (2019) Social Entrepreneurship: Changing the Way Social Workers Do Business. Administration in Social Work, 34 (1): 79-95.

Karpova G., Bogdanova I. (2019) Rol' i mesto predprinimatel'stva v sfere turistskih uslug. [The Role and Place of Entrepreneurship in the Field of Tourism Services] Izvestija Sankt-Peterburgskogo gosudarstvennogo jekonomicheskogo universiteta [Proceedings of the Saint Petersburg State University of Economics], 3 (117): 74-80.

Konda I., Starc J., Rodica B. (2016) Social Challenges are Opportunities for Sustainable Development: Tracing Impacts of Social Entrepreneurship Through Innovations and Value Creation. Economic Themes, (53): 215-233.

Martin L., Osberg S. (2007) Social Entrepreneurship: The Case for Definition. Stanford Social Innovation Review, (33): 28-39.

Moskovskaya A., Soboleva I. (2016) Social Entrepreneurship in the System of Social Policy: International Experience and Prospects of Russia. Studies on Russian Economic Development, 27 (6): 683-688.

Pljuhina A. A. (2016) Sovershenstvovanie metodiki ocenki dejatel'nosti social'nyh predprijatij [Improving the Methodology for Evaluating the Activities of Social Enterprises]. Rossijskoe predprinimatel'stvo [Journal of Russian Entrepreneurship], 17 (13): 1569-1582.

Polyakova A. A. (2018) Sotsial'noe predprinimatel'stvo na primere Permskogo kraya: znachenie, problemy, perspektivy [Social Entrepreneurship on the Example of the Perm Region: Significance, Problems, Prospects]. Ekonomika i biznes: teoriya i praktika [Economics and Business: Theory and Practice], (7): 98-101.

Starshinova A., Borodkina O. (2020) Dejatel'nost' NKO v sfere social'nyh uslug: obshhestvennye ozhidanija i regional'nye praktiki [NGOs' Activities in Social Services: Public Expectations and Regional Practices]. Zhurnal Issledovanii Sotsial'noi Politiki [The Journal of Social Policy Studies], 18 (3): 411-428.

Tanvi G., Rishav R. (2018) Social Entrepreneurship: The Need, Relevance, Facets and Constraints. Journal of Global Entrepreneurship Research, 8 (9): 1-13. 